\title{
A structured approach to brain injury rehabilitation
}

Sir,

The transition from doctor to patient is what most of us dread. Unfortunately, this happened to me. In May 2008, I had a Road Traffic Accident, which resulted in severe brain injury. I would like to recount the patient journey, so that it might help others.

I was driving my Lotus 7, an open top sports car, in Epping Forest. I am told a Stag Deer jumped into the car, causing me to loss control and hit a tree. Paramedics took 90 minutes to release me, unconscious (GCS 9), from my 
car, which was vertically lodged against a tree. I cannot remember any of these and remained amnesic for the next ten weeks.

My external injuries included much bruising, a fractured clavicle, maxilla, and mandible. A magnetic resonance brain scan showed bilateral frontal and temporal lobe contusion. I then suffered a Grand Mal Fit. I was transferred to a neurosurgical unit and spent several days in intensive care. At this stage, my family were told I might die, and that if I survived, I would not be able to care for myself. I required no neurosurgery and was transferred to a rehabilitation ward in my general hospital.

My physical state improved rapidly, but my learning ability and memory remained very poor. I was unaware of the ward I was on, and lived in my own fabricated world. This world was dark and populated by my father, my maternal grandfather, and a young girl. My grandfather and father were already dead but they seemed very much alive. The young girl was an imaginary daughter named Crossie, who was no longer living at home with me. There was an unexplained dispute between us, and I wanted to re-establish links with her. My relationship with the older men was complex. I could not contact them directly; I would make a request and wait for them to respond. I gradually gained insight into my situation and the fabricated world slowly disappeared, although I did discuss it with the speech and language therapists who supervised my care.

My rehabilitation went well with the therapists taking a close interest in my progress. I felt it important that I take a very active role in my rehabilitation, and I devised my own additional rehabilitation strategy. I called this strategy "being back at school" because I needed to relearn a lot. This was very useful for most of the time, but sometimes, the intensity of my determination to relearn produced strange associations. One of my therapists was Australian and I half remembered one of their sports teams was known as the Kangaroos. This then became a fantasy with me remembering cows in the fields in Wales, where I was born, with Kangaroos in the nearby forests. I then wondered how the Kangaroos had got to Australia.

I had become well aware that my memory was poor, and I hoped for reassurance that it would improve. Nobody was able to reassure me, some even suggesting my age would limit my recovery potential. Memory failure limited much of what I attempted to do. For example, when I attempted a "Tube Journey," I found that my mental plan was soon invalidated by memory failure.
Station names became distressing, as I looked at the "Tube Map," unsure which direction I was travelling. I tried to remember my journey plan, but I could not. It seemed the dire prognostication was right. It was very depressing. I could not remember the family home of my teenage years, or what wild animals there were. This changed when I visited a Zoo; what had appeared to be a visit to a mysterious new world was a meeting with old friends. Similarly, when I walked past the old family home, I remembered the content of every room. I learned later that this is experiential memory. Doing it drew on depths that were not reachable by my inefficient thought. This reduced my emotional overlay.

Then suddenly, my memory retrieval started to improve. Spontaneous memories returned without conscious effort. I found that I could now remember my dreams, which I had been unable to do previously. It was clear to me that memories were still stored in my brain, and could still continue to return.

Being a practical person, I needed to have a new model that explained to me what others had been unable to do. I saw my brain as an encyclopaedia with many volumes; the only problem was that the index was no longer functioning. To compare with modern parameters, it was the internet without Wikipedia. Although this analogy may appear primitive or inaccurate, it released the tension I felt and allowed me to pursue a more constructive course.

It seemed to me that exercise might help my brain function improve, as the increased blood flow occurring with exercise could supply my brain with more oxygen and nutrients. I therefore started jogging which helped reduce my weight and improve my balance and coordination.

Although public transport is good in London, I wished to drive again. I had voluntarily terminated my driving license because I had an epileptic fit after the accident. One year later, I was able to come off medication, and remained fit free. I then reapplied for my driving licence and with medical support, regained it. I had to make sure that I was still competent to drive, so I went to the Queen Elizabeth Foundation where my driving ability was tested. I was advised to have a few more driving lessons, which I did, and am now driving successfully.

I am learning music and studying horology. I feel I have made great progress on my recovery journey. I would imagine we all feel we have a life timetable, but it is important to be comfortable with the process, and enjoy its outcome. 
Having made this long journey, I would like to offer advice that may help the following groups on their journeys:

It is important that the patient is made to feel optimistic, and given specific targets to aim for. It should by made clear that this is a long journey and that improvement can be made for up to two years, or more. I think that patients may benefit a great deal from experiential learning. For me, as someone who has an academic and clinical background, experiential learning was more than visiting previously familiar places and meeting people I had known. I found reading my Curriculum Vitae was also experiential, as names of other authors on joint published articles and lists of accomplished activities helped produce many previously forgotten memories. As my insight into my memory deficiency increased, I felt it important to augment the teaching my therapists gave me. I therefore developed a personal strategy that made me try to remember as much about my life as possible, much of this was social homework. It helped increase my confidence.

I can see that this approach might not suit a brain injury patient with dyslexia. I suspect that images and conversation would be far more important than lists for them.

Many friends and relatives have expressed their frustration to me over the difficulty in getting accurate prognostic information, both from the staff looking after $\mathrm{me}$, and from the relevant professional institutions. It is most important to treat this group with a compassionate manner, and give them hope.

These individuals know the patient extremely well, and can sometimes detect improvements, which are not obvious to the professionals looking after the patient.

It is important to listen to patient observations provided by friends and relatives.

Most staff in medicine view brain injury as being largely irreversible. However, Hippocrates recognized more than two thousand years ago that some patients with severe brain injury do recover well and regain much of their previous function.

There are however many factors which will make the patients more likely to have an excellent recovery. Oneto-one sessions with a therapist can be very productive for the patient. Unfortunately, group sessions with several patients can be counterproductive if other patients will not comply with therapists' request, and dilute valuable therapy time. Another key factor is how the patient and the therapist inter-relate, if they do not get on, a successful outcome is unlikely.

DJB Thomas

Diabetes and Endocrinology Unit, The Hillingdon Hospital Trust, Hillingdon, Greater London, UK

Address for correspondence:

Dr. DJB Thomas, The Hillingdon Hospital Trust, Hillingdon, Greater London, UK. E-mail: drdthomas678@btinternet.com

\section{References}

1. Bell JE, Gosden CM. Central nervous system abnormalities--contrasting patterns in early and late pregnancy. Clin Genet 1978;13:387-96.

2. Centers for Disease and Prevention (CDC). Recommendations for the use of folic acid to reduce the number of cases of spina bifida and other neural tube defects. MMWR Recomm Rep 1992;41:1-7.

3. Elwood JM, Elwood JH, Little J. Diet. Elwood JM, Little J, Elwood JH. In. Epidemiology and control of neural tube defects. $1^{\text {st }}$ ed. Oxford, England: Oxford University Press; 1992. p. 521-603.

4. Medical Research Council Vitamin Study Research Group. Prevention of neural tube defects: Results of the medical research council vitamin study. Lancet 1991;338:131-7.

5. Lammer EJ, Sever LE, Oakley GP Jr. Teratogen update: Valproic acid. Teratology 1987;35:465-73.

6. Lemire RJ. Neural tube defects. JAMA 1988;259:558-62.

7. Morin ME, Palacios E. The aplastic hypoplastic lumbar pedicle. Am J Roentgenol Radium Ther Nucl Med 1974;122:639-42.

8. Sadler TW. Mechanisms of neural tube closure and defects. Metab Reta Dev Dis Res Rev 1998;4:247-53.

9. Campbell LR, Sohal GS. The pattern of neural tube defects created by secondary reopening of the neural tube. J Child Neurol 1990;5:336-40.

10. Sakai Y. Neurulation in the mouse: Manner and timing of neural tube closure. Anat Rec 1989;223:194-203.

\begin{tabular}{|l|l|}
\hline \multicolumn{2}{|c|}{ Access this article online } \\
\hline Quick Response Code: & Website: \\
\hline & www.ruralneuropractice.com \\
\cline { 2 - 2 } & \\
\hline
\end{tabular}

